\title{
Photosensitivity of the oceanic copepods Pleuromamma gracilis and Pleuromamma xiphias and its relationship to light penetration and daytime depth distribution*
}

\author{
Edward J. Buskey ${ }^{1}$, Karen S. Baker ${ }^{2}$, Raymond C. Smith ${ }^{3}$, Elijah Swift ${ }^{4}$ \\ ${ }^{1}$ Marine Science Institute, University of Texas at Austin, Port Aransas, Texas 78373, USA \\ ${ }^{2}$ University of California Marine Bio-Optics, Scripps Institution of Oceanography, La Jolla, California 92093, USA \\ ${ }^{3}$ Department of Geography, University of California, Santa Barbara, California 92106 , USA \\ ${ }^{4}$ Graduate School of Oceanography, University of Rhode Island, Kingston, Rhode Island 02881, USA
}

\begin{abstract}
The oceanic copepods Pleuromamma gracilis and Pleuromamma xiphias undergo diel vertical migrations over hundreds of meters in the Sargasso Sea. Near midday during the April 1985 BIOWATT cruise, the peak depth distribution of adult $P$. gracilis was centered near $250 \mathrm{~m}$ while the peak depth distribution of adult $P$. xiphias was centered near $450 \mathrm{~m}$. These depths have a daytime photic environment characterized by very low light intensities of narrow spectral composition. Photosensitivity of each species was estimated by producing an action spectrum for phototaxis. Peak sensitivity of both species was to light of $480 \mathrm{~nm}$, with $50 \%$ of P. gracilis showing negative phototaxis to light of $1.4 \times 10^{14}$ photons $\mathrm{m}^{-2} \mathrm{~s}^{-1}$, and $50 \%$ of P. xiphias showing negative phototaxis to light of $7.2 \times$ $10^{11}$ photons $\mathrm{m}^{-2} \mathrm{~s}^{-1}$. By comparing underwater light intensities measured with a submersible spectroradiometer to daytime depth distribution of $P$. gracilis and $P$. xiphias captured near midday with a MOCNESS net system, it was found that the daytime depth distribution of both species was considerably shallower than the depth at which the underwater light intensity matched their photosensitivity thresholds. Daytime depth distribution was significantly correlated with light intensity, however, with populations being deeper on days with more light penetration.
\end{abstract}

\section{INTRODUCTION}

Two general models have been proposed to explain the role of light in regulating zooplankton vertical migrations. The light preferendum model, which resulted from early photobehavioral experiments, states that the migrator follows a particular light intensity level or 'optimal' range (Rose 1925, Russell 1927). Despite support for this model from experiments involving photobehavior under unnatural, highly directional lighting conditions (see Verheijen 1958 for a review of this experimental problem), there is very little field evidence that zooplankton follow or stay within a particular isolume over a daily cycle (Boden \& Kampa 1967). On the contrary, there are many field reports of migrations that do not track isolumes (e.g. Clarke 1930, 1934,

\footnotetext{
- University of Texas Marine Science Institute Contribution No. 735. BIOWATT Contribution No. 21
}

Russell 1931, Worthington 1931, Johnson, 1938, Kampa \& Boden 1954, Clarke \& Backus 1956). It seems doubtful that most species of zooplankton are capable of attaining the swimming speeds necessary to follow a narrow isolume during sunrise or sunset (Roe 1983). A modified version of the preferendum model states that the migrator acquires a new preferred isolume as the organism adapts to the new light intensity surrounding it at these times. However, Buchanan \& Haney (1980) present strong evidence that 'absolute light intensity in the form of a preferred or optimal zone is not the proximal cause of diel vertical migrations'.

A more recent model states that the migrator responds to the rate and direction of change in light intensity from the adaptation intensity, which is not constant throughout the day (Clarke 1930, Ringelberg 1964, Daan \& Ringelberg 1969). This model can help explain the many field reports of populations not following isolumes. There is also strong support for this 
model from experimental research in which the underwater angular light distribution has been adjusted to reflect a more natural, diffuse condition (Ringelberg 1964, Strickler 1973, Stearns \& Forward 1984b).

A little understood feature of nocturnal vertical migration is the mechanism by which the organism regulates its daytime depth and hence range of vertical movement. In relatively shallow aquatic systems where light above the photosensitivity threshold of the migrating plankters occurs throughout the water column, planktonic organisms may aggregate near the bottom during the day; the bottom presents a physical barrier to further migration. Crab zoeae of the estuarine crab Rhithropanopeus harrisii do not aggregate on the bottom. Forward et al. (1984) found that the mean larval depth in the field occurs near the depth of lower threshold for photosensitivity as measured by phototaxis of dark-adapted zoeae. These authors suggested that day depth for these migrators was determined by the depth of threshold light sensitivity. It seems possible that a similar mechanism may influence the daytime depth distribution of oceanic vertical migrators, although that possibility has not been previously investigated.

Copepods of the genus Pleuromamma form an important component of the oceanic zooplankton in the western Sargasso Sea (Deevey \& Brooks 1977) and other regions of the Atlantic (e.g. Roe 1972, Michel \& Foyo 1976). The 4 most common species in this region Pleuromamma gracilis, Pleuromamma piseki, Pleuromamma abdominalis and Pleuromamma xiphias - are all strong vertical migrators, with the largest species ( $P$. xiphias) having the deepest daytime migration and the smallest species ( $P$. gracilis, $P$. piseki) having shallower daytime distributions (Roe 1972, Bennett \& Hopkins in press). The purpose of this research was to measure the photosensitivities of a large oceanic species ( $P$. xiphias) and a smaller congeneric species (P. gracilis), then compare each photosensitivity with the vertical distribution of each species in the water column and the spectral intensity of light at depth, to determine if photosensitivity is related to the daytime depth distribution of oceanic, migrating zooplankton.

\section{MATERIALS AND ME'THODS}

Copepods for the photosensitivity experiments were collected in the northern $\left(35^{\circ} \mathrm{N}, 70^{\circ} \mathrm{W}\right)$ and southern $\left(24^{\circ} \mathrm{N}, 70^{\circ} \mathrm{W}\right)$ Sargarro Sea during the BIOWATT cruise in April 1985 (Pleuromamma xiphias) and in the Northern Sargasso Sea $\left(35^{\circ} \mathrm{N}, 70^{\circ} \mathrm{W}\right)$ during the BIOWATT cruises in May and August 1987 (Pleuromamma gracilis). Copepods were collected between 21:00 and 22:00 h Eastern Standard Time
(EST). $P$. xiphias were collected using a $1 \mathrm{~m}$ diameter, $500 \mathrm{um}$ mesh net fitted with a large fabric cod end to minimize injury to the copepods (Reeve 1981). $P$. gracilis were collected using $0.5 \mathrm{~m}$ diameter, $333 \mu \mathrm{m}$ mesh nets. Nets were lowered to depths of ca $80 \mathrm{~m}$. towed at slow ship speed $(<1$ knot) and hauled at winch speeds of ca $20 \mathrm{~m} \mathrm{~min}^{-1}$ The contents of the cod ends were immediately diluted and brought into the laboratory for sorting. Adult $P$. gracilis or $P$. xiphias were isolated in a darkened room under dim red illumination using large bore $(8 \mathrm{~mm})$ pipettes, and each species was held separately in filtered seawater in darkened $15^{\circ} \mathrm{C}$ incubators for at least $2 \mathrm{~h}$ of dark adaptation before experimentation. To minimize the effects of possible endogenous rhythms in photosensitivity, all experiments were performed in a light-tight room on board ship between 23:00 and 04:00 h (EST).

Light for the photosensitivity experiments was provided by a $100 \mathrm{~W}$ quartz halogen lamp (Oriel model 6333). Wavelength was controlled by interference filters (Oriel, half band pass $10 \mathrm{~nm}$ ) and intensity was controlled by neutral density filters. The light source was surrounded by a light shield to prevent leakage of stray light. A hole in the wall of the shield allowed passage of the stimulus light.

Phototaxis was measured using a horizontal plexiglass trough $(40 \mathrm{~cm}$ long $\times 6 \mathrm{~cm}$ wide $\times 8 \mathrm{~cm}$ high) to separate possible interactions between photoresponses and gravity responses. The chamber contained 5 sections of equal size separated by removable partitions and was positioned so that the stimulus light beam passed along the long axis.

The same procedure was used for each experiment. In complete darkness, 10 adult Pleuromamma of a single species (P. gracilis or $P$. xiphias) held in a $500 \mathrm{ml}$ jar were gently poured into the center section of the partially filled plexiglass trough with the partitions inserted. The copepods were allowed to adjust to the chamber for $3 \mathrm{~min}$. The partitions were then replaced, and the number of copepods in each section of the chamber was recorded. Copepods found in the section closest to the light source were considered positively phototactic while those found in the section farthest from the light source were considered negatively phototactic. The trough was washed between trials with filtered seawater to remove all tested copepods. Copepods were tested only once and then preserved for later identification. Samples found to contain copepods other than the single intended species ( $P$. gracilis or $P$. xiphias, depending on the experiment) were not included in analysis. Control groups were tested in the same way except without the light stimulus.

Using this procedure, 16 wavelengths from 400 to $700 \mathrm{~nm}$ at $20 \mathrm{~nm}$ increments were tested at 4 to 8

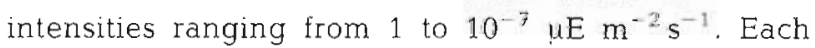


wavelength-intensity combination was tested 2 to 4 times. The results of these experiments were used to determine the action spectrum for negative phototaxis.

Vertically stratified zooplankton samples were collected using a Multiple Opening/Closing Net and Environmental Sensing System (MOCNESS) $\left(1 \mathrm{~m}^{2}\right.$ mouth opening, $153 \mu \mathrm{m}$ mesh) (Wiebe et al. 1976, 1985). This opening-closing net system allows for collection of 9 sequential zooplankton samples along with in situ environmental information (depth and temperature) and sampling data (volume filtered and net angle). On the 1985 BIOWATT cruise, the MOCNESS tow series consisted of oblique tows from $800 \mathrm{~m}$ to the surface in intervals of $800-600,600-500,500-400$, $400-300,300-200,200-100,100-50$ and $50-0 \mathrm{~m}$. Two day and 2 night tow series, each beginning shortly after noon and midnight, were collected at each station. Samples were preserved in $4 \%$ buffered formalin. Zooplankton samples were later analyzed for the abundance of Pleuromamma gracilis and $P$. xiphias. The samples were split with a Folsom plankton splitter and from $1 / 2$ to $1 / 32$ of the sample was counted, depending on the density of the sample and the abundances of the desired species.

Light penetration at depth was calculated based on measurements of downwelling spectral irradiance made with the Bio-Optical Profiling System (BOPS) (Smith et al. 1984) at 11 wavelengths $(410,411,465$, $488,520,540,560,589,625,671,694 \mathrm{~nm})$ continuously profiled through the upper $200 \mathrm{~m}$. Light intensities below $200 \mathrm{~m}$ were estimated based on the wavelength specific diffuse attenuation coefficients $K(w l)$, determined for depths below the chlorophyll maximum and upon the assumption that $K(w)$ reached the value of that for clean waters (Smith \& Baker 1981) at $300 \mathrm{~m}$

\section{RESULTS}

Pleuromamma gracilis and Pleuromamma xiphias displayed mainly negative phototaxis in these experiments. 'Positive phototaxis' (copepods in chamber section closest to light) rarely exceeded $15 \%$, with a mean of $7.1 \pm 7.5 \%$ (SD) for $P$. gracilis $(n=175)$ and $6.0 \pm$ $5.6 \%$ for $P$. xiphias $(n=297)$ for all wavelength-intensity combinations tested. In control experiments, 17.8 $\pm 12.8 \%$ and $16.5 \pm 13.1 \%$ of the $P$. xiphias $(n=25)$ were found in the sections of the trough closed and farthest from the light, respectively, and $18.8 \pm 16.8 \%$ and $20.4 \pm 14.2 \%$ of the P. gracilis $(n=25)$ were found in the sections of the trough farthest and closest to the light. The amount of negative phototaxis exhibited by $P$. gracilis and $P$. xiphias depended on stimulus intensity and wavelength. For the spectral region of greatest photosensitivity $(420$ to $540 \mathrm{~nm})$ a roughly hyperbolic

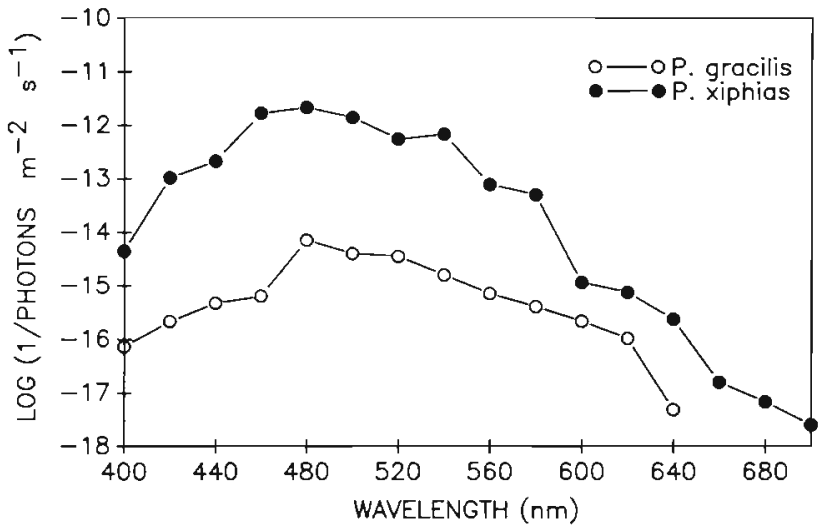

Fig. 1. Pleuromamma gracilis and P. xiphias. Action spectrum of negative phototaxis. Quantal intensities required to evoke $50 \%$ response levels are plotted

stimulus intensity versus response relationship for negative phototaxis was found.

To construct an action spectrum for negative phototaxis in Pleuromamma gracilis and P. xiphias, the percent response data were arcsine-transformed (Sokal \& Rohlf 1981) and a linear regression on quantal light intensity (log-transformed) was performed for points lying on the steeply rising portion of the stimulus response curve for each wavelength. The regression equation was used to estimate the quantal intensity necessary to elicit an intermediate response level of $50 \%$. The shape of the action spectrum (Fig. 1) indicates that both $P$. gracilis and $P$. xiphias are most sensitive to blue-green light with a maximum sensitivity at $480 \mathrm{~nm}$. Photosensitivity of $P$. xiphias is greatest at wavelengths from 460 to $540 \mathrm{~nm}$, and drops abruptly at wavelengths outside this range. $P$. gracilis had a broader range of maximal spectral sensitivity, from ca 420 to $620 \mathrm{~nm}$.

To determine the photosensitivity threshold for each species, percent negative phototaxis data from all experimental wavelength-intensity combinations were pooled into groups at intervals of 5 percentage points (e.g. $2.5-7.5 \% ; 7.5-12.5 ; 12.5-17.5 \%$ ); each group was compared to the percent 'negative phototaxis' in the control groups. For both species the lowest percent group which showed a significant difference from the controls was the 27.5-32.5\% negative phototaxis group (ANOVA, $\alpha=0.05$ ). We therefore chose a $30 \%$ response to define the threshold for negative phototaxis in both species. The same regression equation used to determine the $50 \%$ response level of phototaxis was used to determine the $30 \%$ response (threshold) level. For the wavelength of maximum photosensitivity, $480 \mathrm{~nm}$, the threshold response intensities of Pleuromamma gracilis and $P$. xiphias were found to be $9.5 \times 10^{12}$ and $7.7 \times 10^{10}$ photons $\mathrm{m}^{-2} \mathrm{~s}^{-1}$, respectively.

The daytime depth distributions of adult 

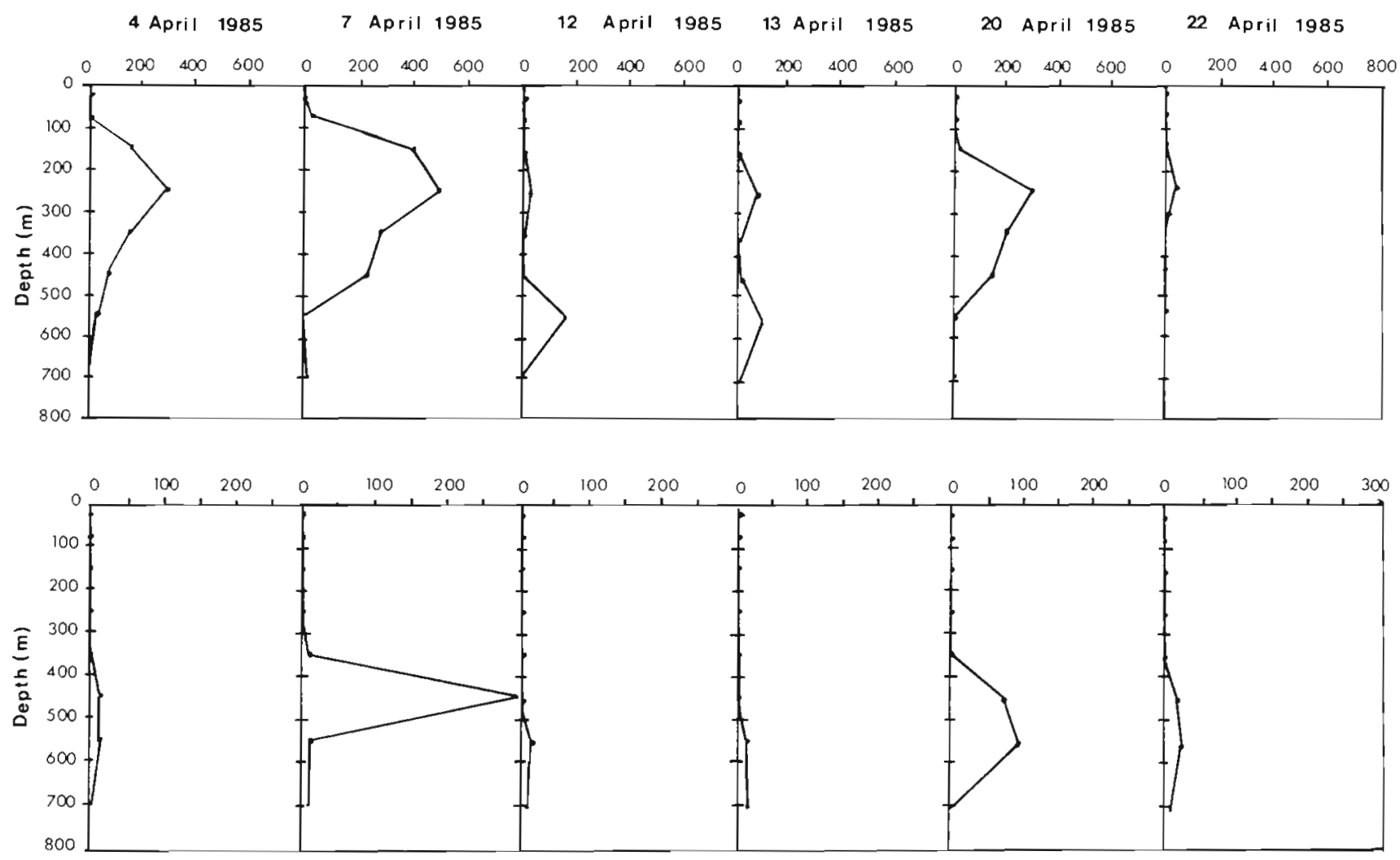

Fig. 2. Pleuromamma gracilis (top) and P. xiphias (bottom). Daytime vertical distribution at a station in the northern Sargasso Sea $(4,7,20,22 \mathrm{April})$ and a station in the southern Sargasso Sea $(12,13$ April)

Pleuromamma gracilis and $P$. xiphias, based on enumeration of MOCNESS samples, are shown in Fig. 2. At the northern station $\left(35^{\circ} \mathrm{N}, 70^{\circ} \mathrm{W}\right)$, maximum daytime abundance of $P$. xiphias occurred at depths between 400 and $600 \mathrm{~m}$, while at the southern station, peak distributions occurred at depths between 500 and $800 \mathrm{~m}$. The maximum daytime abundance of $P$. gracilis occurred between 100 and $500 \mathrm{~m}$ at the northern station and between 200 and $600 \mathrm{~m}$ at the southern station. For each set of depth-stratified MOCNESS samples the mean depth of each species, the depth above which $50 \%$ of the adults of that species were captured, was calculated. This depth was defined as the population center. The depth of the population center was used for comparison to the depth where the light intensity matched the photosensitivity threshold of each species.

Representative examples of the distribution of spectral irradiance at depths of $350,450,550$ and $700 \mathrm{~m}$ are shown in Fig. 3. These depths correspond to the midpoints of the 4 deepest MOCNESS samples (300-400, $400-500,500-600,600-800 \mathrm{~m}$ ). Spectral irradiance data taken near noon EST were available for all of the days that MOCNESS tows were taken. MOCNESS tows followed deployment of the BOPS on these dates, so there was a 1 to $2 \mathrm{~h}$ lag between the collection of the optical data and the capture of the copepods. Comparison of measures of total light energy from the abovewater pyranometer at the time of BOPS and MOCNESS tows were used to correct for changes in underwater spectral irradiance. It was assumed that the wavelength specific attenuation coefficients did not change over the 1 to $2 \mathrm{~h}$ interval.

The BOPS casts taken at Stns 4 and 19 were located in the northern Sargasso Sea $\left(35^{\circ} \mathrm{N}, 70^{\circ} \mathrm{W}\right)$ and all showed a similar pattern of spectral irradiance vs depth, with peak irradiance in the blue-green region $(465,488 \mathrm{~nm})$. Irradiance dropped off gradually for shorter wavelengths $(410,441 \mathrm{~nm})$ in the northern Sargasso Sea and more sharply for longer wavelengths at both locations, but all measurements dropped off scale between 560 and $589 \mathrm{~nm}$ (Fig. 3). Casts taken at Stn 10 in the southern Sargasso Sea $\left(24^{\circ} \mathrm{N}, 70^{\circ} \mathrm{W}\right)$ differed mainly in the increased irradiance at the short wavelengths $(410,441 \mathrm{~nm})$ and the overall increased irradiance at depth at all wavelengths, due to increased clarity of the more oligotrophic surface waters as well as to the increased surface intensity because of lower latitudes and clearer skies. The wavelength of peak light transmission varied with depth at the northern station $\left(35^{\circ} \mathrm{N}, 70^{\circ} \mathrm{W}\right)$, with peak transmission shifting toward shorter wavelengths with increasing depth. The 

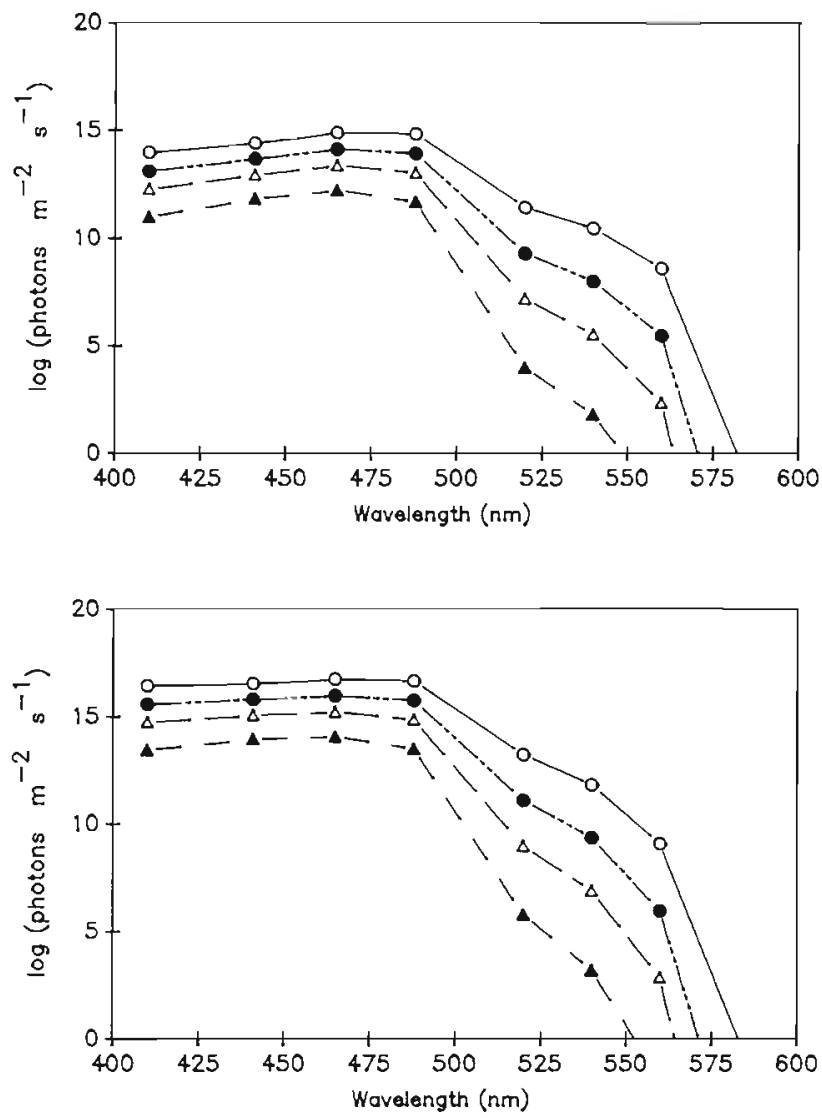

Fig. 3. Spectral irradiance at 4 depths corresponding to the mid-depth of samples collected with the MOCNESS $(350,450$, 550 and $700 \mathrm{~m}$ ) for 2 representative casts taken in the northern Sargasso Sea (top) on 22 April at 12:50 h EST and for the southern Sargasso Sea (bottom) on 12 April at 12:45 h EST (o) Spectral irradiance at $350 \mathrm{~m} ;(\bullet)$ at $450 \mathrm{~m} ;(\Delta)$ at $550 \mathrm{~m} ;(\mathbf{\Lambda})$ at $700 \mathrm{~m}$

wavelength of peak transmission shifted from $488 \mathrm{~nm}$ in subsurface waters to $465 \mathrm{~nm}$ at depths of ca $350 \mathrm{~m}$. In the southern Sargasso Sea $\left(24^{\circ} \mathrm{N}, 70^{\circ} \mathrm{W}\right)$ peak transmission remained at $465 \mathrm{~nm}$ throughout the extent of the water column sampled. Since the wavelengths we used to test photosensitivity did not match the wavelengths measured by the BOPS, we estimated underwater light intensities at 460 and $480 \mathrm{~nm}$ by linear interpolation to estimate the depth which would correspond to the photosensitivity threshold of each species (Table 1).

\section{DISCUSSION}

The consistent negative phototaxis of Pleuromamma gracilis and Pleuromamma xiphias over a wide range of light intensities is in contrast to previous studies of estuarine copepods (Stearns \& Forward 1984a) and freshwater copepods (Swift \& Forward 1984) which show primarily positive phototaxis under comparable treatment. However, Shallek $(1942,1943)$ found that Acartia tonsa sank in light that is not highly directional, but moved toward a directional source of light. Thus records of positive phototaxis may be the result of using directional light sources, in some cases (see review by Forward 1988). However, in studies where organisms exhibited negative phototaxis in a directional light field, they also exhibited negative phototaxis in a simulated natural angular light distribution (Forward 1985, $1986 a$,b). Unlike the organisms previously tested, however, $P$. gracilis and $P$. xiphias live in a deep oligotrophic, oceanic ecosystem, where vertical migrations of 200 to $>500 \mathrm{~m}$ extent (Fig. 2) are never limited by the depth of the water column. With increasing depth the angular distribution of light becomes broader and the direction of maximum radiance shifts from an oblique angle toward a uniform distribution around the zenith (Jerlov 1970). Thus it is not surprising that their photobehavior may differ from that of coastal and estuarine vertically migrating zooplankton which may remain near the bottom but within the photic zone during the day. Although we have not directly demonstrated that negative phototaxis will occur for Pleuromamma spp. in nature, independent evidence that negative phototaxis may occur among oceanic zooplankton and micronekton comes from observations that descending artificial lights can force a sonic scattering layer to descend (Edgerton \& Bascom 1982), although this is a highly directional light source, not a natural angular light distribution.

Both Pleuromamma gracilis and $P$. xiphias had maximum photosensitivity at wavelengths of $480 \mathrm{~nm}$ (Fig. 1). This maximum corresponds well to the wavelengths that are best transmitted through seawater and that therefore dominate the photic environment of the mesopelagic (Jerlov 1976). The photosensitivity of these species also corresponds well to the dominant wavelengths of most marine bioluminescence (Herring 1983, Widder et al. 1983, Latz et al. 1988). These results support the sensitivity hypothesis (Munz 1958) which states that the spectral position of visual sensitivity is matched to the dominant environmental distribution of spectral irradiance. The action spectrum of $P$. xiphias is somewhat more peaked than that of $P$. gracilis, and the difference between the 2 action spectra decreases at longer wavelengths. The action spectra for these 2 species are not as flat as that found for the estuarine copepod Acartia tonsa, however, which shows nearly uniform sensitivity from 453 to $620 \mathrm{~nm}$ (Stearns \& Forward 1984a).

The precise role of light on the vertical migration of oceanic copepods such as Pleuromamma spp. has not been well defined. For migrating copepods living in shallow systems, the rate and direction of change in 
Table 1. Pleuromamma gracilis and $P$. xiphias. Relationship between depth of photosensitivity threshold isolume and mean depth distribution of adult copepods during the day

\begin{tabular}{|lcccccc|}
\hline $\begin{array}{l}\text { Date } \\
(1985)\end{array}$ & Location & Time (EST) & $\begin{array}{c}\text { Depth of P. gracilis } \\
\text { photosensitivity } \\
\text { threshold isolume } \\
(\mathrm{m})\end{array}$ & $\begin{array}{c}\text { Mean depth of } \\
\text { adult P. gracilis } \\
\text { population (m) }\end{array}$ & $\begin{array}{c}\text { Depth of } P \text {. xiphias } \\
\text { photosensitivity } \\
\text { threshold isolume } \\
\text { (m) }\end{array}$ & $\begin{array}{c}\text { Mean depth of } \\
\text { adult } P \text {. xiphias } \\
\text { population (m) }\end{array}$ \\
\hline $4 \mathrm{Apr}$ & $35^{\circ} \mathrm{N}, 70^{\circ} \mathrm{W}$ & $15: 35 \mathrm{~h}$ & 502 & 287 & 780 & 73 \\
$7 \mathrm{Apr}$ & $35^{\circ} \mathrm{N}, 70^{\circ} \mathrm{W}$ & $14: 10 \mathrm{~h}$ & 490 & 275 & 1019 & 459 \\
$12 \mathrm{Apr}$ & $24^{\circ} \mathrm{N}, 70^{\circ} \mathrm{W}$ & $12: 45 \mathrm{~h}$ & 786 & 505 & 1086 & 612 \\
$13 \mathrm{Apr}$ & $24^{\circ} \mathrm{N}, 70^{\circ} \mathrm{W}$ & $13: 15 \mathrm{~h}$ & 730 & 423 & 320 & 634 \\
$20 \mathrm{Apr}$ & $35^{\circ} \mathrm{N}, 70^{\circ} \mathrm{W}$ & $13: 50 \mathrm{~h}$ & 515 & 283 & 909 & 511 \\
$22 \mathrm{Apr}$ & $35^{\circ} \mathrm{N}, 70^{\circ} \mathrm{W}$ & $12: 50 \mathrm{~h}$ & 624 & & & 537 \\
\hline
\end{tabular}

light intensity may be the most important cues for initiating short distance migrations. At sunrise the rate of light intensity increase induces downward migration. For estuarine species such as Acartia tonsa, this may result from an increase in time spent sinking between hops, rather than an active downward migration (Stearns \& Forward 1984b). When the organisms reach the bottom they adapt to that particular light level. At sunset the rate of decrease in light intensity induces upward migration. In deeper aquatic environments, zooplankton do not migrate to the bottom but descend to a particular range of depths in the water column. It has been suggested that migrating zooplankton follow a particular or preferred light intensity (preferendum hypothesis; Russell 1927): zooplankton migrate to follow a particular isolume as it descends near dawn and ascends near sunset. Studies of sonic scattering layers such as those of Boden \& Kampa (1967) seem to support this hypothesis. More recent studies of mesopelagic zooplankton suggest that most migrators have diffuse vertical distributions over several orders of magnitude of light intensity and may swim too slowly to keep up with isolumes (Roe 1983, $1984 a, b)$. Negative phototaxis might drive the daytime descent of some species, even if they cannot keep up with the descending isolumes. They would continue their descent until ambient light intensities no longer stimulated a phototactic response. In nature, the depth of daytime distribution may be influenced by ambient light intensities, as zooplankton often occur at greater depths as water clarity increases (e.g. Rothlisberg 1982, Gliwitz 1986). We have found a similar pattern in this study, with Pleuromamma spp. having a greater daytime depth distribution in the clearer waters of the southern Sargasso Sea than in the more turbid northern Sargasso Sea (Table 1).

If the extent of daytime descent is regulated by the photosensitivity of the Pleuromamma species, the daytime depth distribution should correspond to the depth at which light intensities match the lower response threshold for photosensitivity. It should then be possible to predict daytime depth distributions of both species by comparing their intensity threshold for negative phototaxis to the distribution of perceived spectral irradiance at depth. The predicted depth of maximum daytime abundance near noon based on the dark-adapted phototaxis threshold was significantly correlated $(\alpha=0.05)$ with actual daytime depth distributions $(r=0.89$ for $P$, gracilis and 0.96 for $P$. xiphias), although both species are consistently shallower in distribution than predicted (Table 1). Perhaps it is not reasonable to expect $50 \%$ of the population to migrate below a light level which represents the threshold of detection for the population, when a much smaller fraction of the population responds to this intensity in the laboratory. The $50 \%$ response level (Fig. 1) corresponds more closely to the mean population depth, but is still shallower than expected (Fig. 4). The daytime depth distribution of both species of Pleuromamma were spread over depth ranges of 200 to

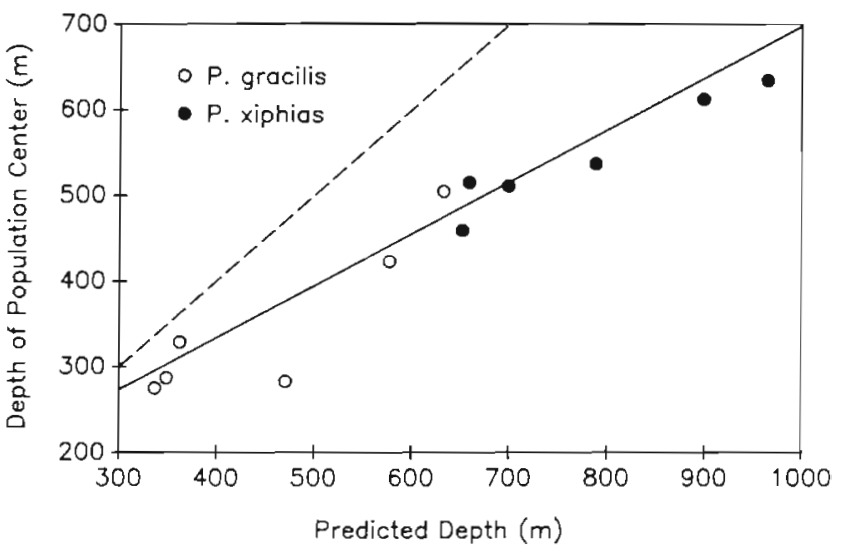

Fig. 4. Pleuromamma gracilss and P. xiphias. Actual mid-point in depth distribution, plotted against the predicted average depth distribution based on the $50 \%$ response photosensitivity of the species and the spectral irradiance at depth ( $r=$ 0.965 ). Dashed line: line of equality where depth of population center equals predicted depth 
$500 \mathrm{~m}$ (Fig. 2). Light intensities vary by several orders of magnitude over this depth range. Either there is considerable variability in the photosensitivities of individual copepods, or factors in addition to light must also be influencing the daytime descent of the copepods. The calculated depth of the photosensitivity threshold of each species was consistently deeper than the population center by 200 to $300 \mathrm{~m}$ for $P$. gracilis and by 300 to $400 \mathrm{~m}$ for $P$. xiphias. The depth of the photosensitivity threshold of $P$. gracilis corresponds more closely to its maximum depth (Table 1 ; Fig. 2). This may also be true for $P$. xiphias, although the depth of the photosensitivity threshold was often greater than the deepest sample we collected (600 to $800 \mathrm{~m}$ ).

Forward et al. (1984) found that larvae of the estuarine crab Rhithropanopeus harrisii have daytime depth distributions which correspond closely to the depth of the isolume that matches their dark-adapted photosensitivity threshold. The behaviors that allow these larvae to aggregate at this isolume include a negative geotaxis in darkness which changes to a sinking response upon exposure to a perceptible increase in light intensity. Although we did not test specifically for negative geotaxis in either species of Pleuromamma, we assume that a similar mechanism must exist to prevent them from migrating deeper into the water column where surface light intensity would be below their detection thresholds. The effects of hydrostatic pressure on the swimming behavior of deep-migrating oceanic copepods is unknown, but pressure may also play a role in depth regulation.

The observation that daytime distributions of Pleuromamma are shallower than the depths with light intensities corresponding to their photosensitivity thresholds could be due to the rapid descent of isolumes at dawn, which could cause the copepods to become photoadapted to ambient light intensities as they descend, leading to a reduction in their photosensitivity. Stearns \& Forward $(1984 \mathrm{a}, \mathrm{b})$ have shown that both phototaxis and responsiveness of Acartia tonsa to changes in light intensity decline as adaptation intensity increases. If photoadaptation were occurring, once the depth of the lowest light level perceived is reached, the copepods should begin to adapt to lower light levels. This should cause the photosensitivity threshold to shift to a lower intensity and for the descent to continue. This sequence could continue until an animal reaches the depth of its absolute lowest (dark-adapted) photoresponse threshold. However, we do not know how long this hypothesized process of photoadaptation would take and if the copepods would have enough time to descend to the level of their maximum photosensitivity before light intensities in the water column began to decrease and the copepods began their ascent. Further research on photoadaptation of these species is needed.
One of the earliest explanations for the phenomenon of vertical migration in zooplankton was that these movements reduced predation pressure from visual predators (Russell 1927). Pleuromamma spp. are important prey items for micronekton because of their abundance and co-occurrence with common myctophid and penaeid shrimp species (Merrett \& Roe 1974, Clarke 1980, Hopkins \& Baird 1981, 1985, Hopkins 1982). The correlation between light cycles and the timing and extent of migration is consistent. with this hypothesis, since Pleuromamma spp. begin their descent near dawn and spend the day at depths with very low light levels (Roe 1972, Bennett \& Hopkins in press). If this hypothesis is correct, then minimum daytime depths should correspond to the depths at which the organisms stop presenting perceptible targets to their predators (Angel 1985). Therefore we might expect larger zooplankton to migrate to deeper daytime depths than smaller zooplankton. Fig. 5 shows the mean vertical distribution of $P$. gracilis and P. xiphias based on all 6 MOCNESS tows. $P$. gracilis, the smaller of the species, has the shallowest daytime distribution, while $P$. xiphias has deeper daytime distributions. For both species, the smaller juvenile stages have shallower daytime distributions. Our hypothesis about the relationship between photosensitivity and daytime light intensity at depth is also consistent with the predation hypothesis since $P$. gracilis is less photosensitive than P. xiphias.

Another possible explanation for the difference in depth distribution between the larger and smaller species is that the larger species are capable of traveling greater distances during the same amount of time. There has been some controversy as to whether the daytime descent of oceanc zooplankton is accomplished through active swimming or passive sinking, however. Rudjakov $(1970,1973)$ has suggested that the downward vertical migration of crustacean zooplankton could be due entirely to passive sinking. Sinking rates of 20 species of anaesthetized copepods ranged from 1.8 to $47.4 \mathrm{~m} \mathrm{~h}^{-1}$, with most species sinking at about $20 \mathrm{~m} \mathrm{~h}^{-1}$. Measurements of the sinking rate of anaesthetized adult Pleuromamma xiphias and $P$. gracilis (Buskey unpubl.) show a sinking rate of 40.3 $\mathrm{mh}^{-1}$ and $11.0 \mathrm{~m} \mathrm{~h}^{-1}$, respectively. The difference between the mean daytime distribution (noon) and the mean night-time distribution (midnight) is ca $400 \mathrm{~m}$ for $P$. xiphias and ca $250 \mathrm{~m}$ for $P$. gracilis. It would take ca $10 \mathrm{~h}$ for $P$. xiphias and nearly $24 \mathrm{~h}$ for $P$. gracilis to sink passively through this depth interval. If daytime descent of vertically migrating copepods begins at dawn, less than $8 \mathrm{~h}$ would be available to reach maximum daytime depth. Some active swimming must therefore be involved in their descent. 


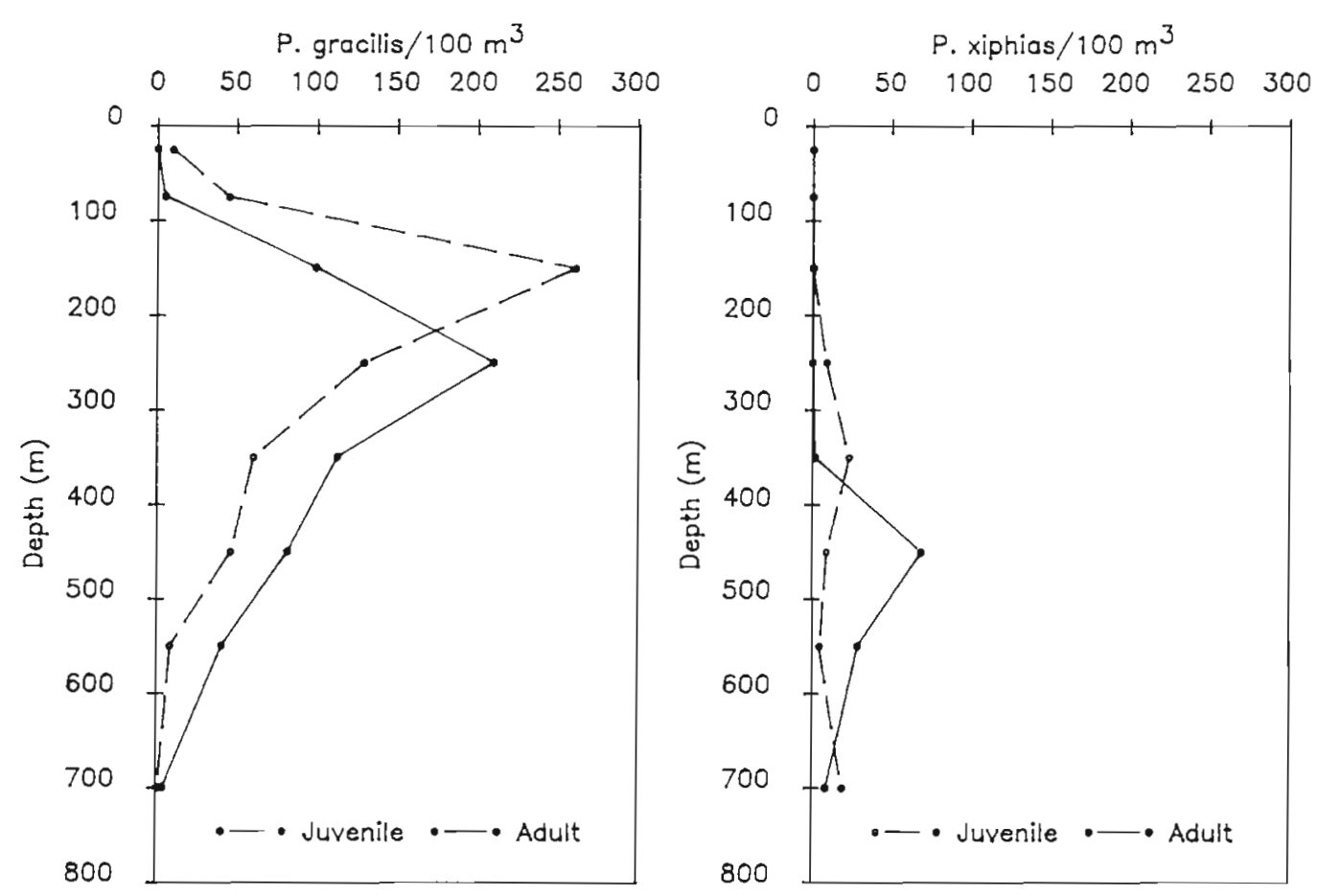

Fig. 5. Pleuromamma gracilis and P. xiphias. Average daytime depth distributions of adults and juvenile developmental stages for 6 MOCNESS tows

The average non-directional swimming speeds of Pleuromamma gracilis and $P$. xiphias in the dark are ca 13.4 and $14.7 \mathrm{~mm} \mathrm{~s}^{-1}$ (Buskey \& Swift unpubl.). These speeds would allow them to cover the distance between mean daytime and night-time distribution peaks in less than $8 \mathrm{~h}$ only if their swimming were highly directional. Estimates of migration distance based on changes in mean population depth distribution yield only minimal estimates of range or velocity of vertical migrants, since the entire population does not always migrate and individuals are often moving in directions opposite to the mean direction of migration (Pearre 1979). Therefore it seems possible that either negative phototaxis or photokinetic behavior induces active downward migrations in Pleuromamma spp., until the ambient light regime matches the limit of their photosensitivity or until surface light intensities begin to decrease and the isolumes start to ascend.

In this study we have considered only the effects of light in regulating the daytime position of vertically migrating, adult oceanic copepods. Other exogenous factors may influence diurnal vertical migration, including temperature, salinity and hydrostatic pressure. In the Sargasso Sea and other oceanic environments, salinity is usually nearly constant over the range of deep migrating species such as Pleuromanma spp. Temperature may play a role in regulating the extent of vertical migration of oceanic copepods especially with respect to seasonal patterns
(Moore \& Bauer 1960) or distribution across thermal boundaries such as the Gulf Stream (Wishner \& Alison 1986). Very little is known about the role of hydrostatic pressure in regulating the depth of oceanic copepods, although it may play a role at least in depth regulation. of meroplanktonic larvae of crustaceans (reviewed by Sulkin 1984). However, on a daily basis, light seems to be the most important factor influencing the extent of daytime descent during vertical migration, since the mean depths of the adult Pleuromamma populations correlate significantly to the depths to which light perceptible to Pleuromamma penetrates the sea.

Acknowledgements. This research was supported by the Office of Naval Research (Contract N00014-87-K-0477 to E.J.B. and contract N00014-81-C-0062 to E.S.). Technical assistance was provided by Rob Lane, Chris Mann, Jody Dugas and Jim Sullivan. Helen Garrett assisted with manuscript preparation. We thank R. B. Forward, Jr, D. E. Stearns and 2 anonymous reviewers for their comments on this manuscript.

\section{LITERATURE CITED}

Angel, M. V (1985). Vertical migration in the oceanic realm: possible causes and possible effects. In: Rankin. M. A. (ed.) $\therefore$ figration: mechanisms and adaptive significance. Contr. mar Sci. (Suppl.) 27: 45-70

Bennett, J. L., Hopkins, T. L. (in press). Aspects of the ecology of the calanoid copepod genus Pleuromamma in the eastern Gulf of Mexico. Contr, mar. Sci. 31 
Boden, B. P., Kampa, E. M. (1967). The influence of natural light on the vertical migrations of an animal community in the sea. Symp. Zool. Soc. Lond. 19: 15-26

Buchanan, C., Haney, J. F. (1980). Vertical migration of zooplankton in the arctic: a test of the environmental controls. Am. Soc. Limnol. Oceanogr. Spec. Symp. 3: 69-79

Clarke, G. L. (1930). Change in phototropic and geotropic signs in Daphnia induced by changes in light intensity. J. exp. Biol. 7. 109-131

Clarke, G. L. (1934). Further observations on the diurnal migration of copepods in the Gulf of Mexico. Biol. Bull. mar, biol. Lab., Woods Hole 67: 432-455

Clarke, G. L., Backus, R. H. (1956). Measurements of light penetration in relation to vertical migration and records of luminescence of deep-sea animals. Deep Sea Res. 4: 1-14

Clarke, T A. (1980). Diets of fourteen species of vertically migrating mesopelagic fishes in Hawaiian waters. Fish. Bull. U. S. 74: 619-640

Daan, N., Ringelberg, J. (1969). Further studies on the positive and negative phototactic reaction of Daphnia magna Straus. Neth. J. Zool. 19: 525-540

Deevey, G. B., Brooks, A. L. (1977). Copepods of the Sargasso Sea off Bermuda: species composition and vertical and seasonal distribution between the surface and 2000 meters. Bull. mar. Sci. 27: 256-291

Edgerton, H. E., Bascom, W. (1982). Sonic scattering layers influenced by artificial light. Bull. mar. Sci. 32: 629-632

Forward, R. B., Jr. (1985). Behavioral response of larvae of the crab Rhithropanopeus harrisii (Brachyura: xanthidae) during diel vertical migration. Mar. Biol. 90: 9-18

Forward, R. B., Jr. (1986a). A reconsideration of a shadow response of a larval crustacean. Mar. behav. Physiol. 12: 99-113

Forward, R. B., Jr. (1986b). Behavioral responses of a sandbeach amphipod to light and pressure. J. exp. mar. Biol Ecol. 102: 55-74

Forward, R. B., Jr. (1988). Diel vertical migration: zooplankton photobiology and behavior. Oceanogr. mar. Biol. A. Rev. 26: 361-393

Forward, R. B., Jr., Cronin, T W., Stearns, D. E. (1984) Control of diel vertical migration: photoresponses of a larval crustacean. Limnol. Oceanogr. 29: 146-154

Gliwicz, Z. M. (1986). A lunar cycle in zooplankton. Ecology $67 \cdot 883-897$

Herring, P. J. (1983). The spectral characteristics of luminous marine organisms. Proc. R. Soc. Lond. B 220: 183-217

Hopkins, T. L. (1982). The vertical distribution of zooplankton in the eastern Gulf of Mexico. Deep Sea Res. 29: 1069-1083

Hopkins, T. L., Baird, R. C. (1981). Trophodynamics of the fish Valenciennellus tripunctulatus. I. Vertical distribution, diet and feeding chronology. Mar. Ecol. Prog. Ser. 4: 1-10

Hopkins, T L., Baird, R. C. (1985). Aspects of the trophic ecology of the mesopelagic fish Lampanyctus alatus (Family Myctophidae) in the eastern Gulf of Mexico. Biol. Oceanogr. 3: 285-313

Jerlov, N. G. (1970). Light. General introduction. In: Kinne, O. (ed.) Marine ecology, Vol. 1, Part 1. Wiley-Interscience, New York, p. 95-102

Jerlov, N. G. (1976). Marine optics. Elsevier oceanography series, Vol. 14. Elsevier Science, New York

Johnson, W H. (1938). The effect of light on the vertical movements of Acartia clausi (Giesbrecht). Biol. Bull. mar. biol. Lab., Woods Hole 75; 106-118

Kampa, E. M., Boden, B. P. (1954). Submarine illumination and the twilight movements of a sonic scattering layer. Nature, Lond. 174: 869-871
Latz, M. I., Frank, T. M., Case, J. F. (1988). Spectral composition of epipelagic organisms from the Sargasso Sea. Mar Biol. 98: 441-446

Merrett, H. R., Roe, H. S. J. (1974). Patterns and selectivity in the feeding of certain mesopelagic fishes. Mar Biol. 28: $115-126$

Michel, H. B., Foyo, M. (1976). Caribbean zooplankton. Part 1. Office of Naval Research, Washington, D.C.

Moore, H. B., Bauer, J. C. (1960). An analysis of the relation of the vertical distribution of three copepods to environmental conditions. Bull. mar Sci. 10:430-443

Munz, F. W. (1958). The photosensitive retinal pigments of fishes from relatively turbid coastal waters. J. gen. Physiol. 42: 445-459

Pearre, S., Jr. (1979). Problems of detection and interpretation of vertical migration. J. Plankton Res. 1: 29-44

Reeve, M. R. (1981). Large cod-end reservoirs as an aid to the live collection of delicate zooplankton. Limnol. Oceanogr. 26: $577-580$

Ringelberg, J., Jr. (1964). The positively phototactic reaction of Daphnia magna Straus: A contribution to the understanding of diurnal vertical migration. Neth. J. Sea Res. 2 319-406

Roe, H. S. J. (1972). The vertical distribution and diurnal migrations of calanoid copepods collected on the SOND cruise, 1965. III. Systematic account: Families Euchaetidae up to and including the Metridiidae. J. mar. biol. Ass. U. K. 52: 525-552

Roe, H. S. J. (1983). Vertical distribution of euphausiids and fish in relation to light intensity in the Northeastern Atlantic. Mar. Biol. 77: 287-298

Roe, H. S. J. (1984a). The diel migrations and distributions within a mesopelagic community in the North East Atlantic. 2. Vertical migrations and feeding of mysids and decapod crustaceans. Prog. Oceanogr 13: 269-318

Roe, H. S. J. (1984b). The diel migrations and distributions within a mesopelagic community in the North East Atlantic. 4. The copepods. Prog. Oceanogr. 13: 353-388

Rose, M. (1925). Contribution à l'étude de la biologie du plancton. Le problème des migrations verticales journalières. Arch. Zool. exp. gén. 64: 387-542

Rothlisberg, P. C. (1982). Vertical migration and its effect on dispersal of penaeid shrimp larvae in the Gulf of Carpentaria, Australia. Fish. Bull. U. S. 80: 541-554

Rudjakov, J. A. (1970). The possible causes of diel vertical migrations of planktonic animals. Mar. Biol. 6: 98-105

Rudjakov, J. A. (1973). Rate of passive vertical movernent of planktonic organisms. Oceanology 12: 886-889

Russell, F. S. (1927). The vertical distribution of plankton in the sea. Biol. Rev. Biol. Proc. Cambridge Phil. Soc. 2: 213-262

Russell, F. S. (1931). The vertical distribution of marine macroplankton. XI. Further observations on diurnal changes. J. mar. biol. Ass. U. K. 17: 767-775

Shallek, W. (1942). The vertical migration of the copepod Acartia tonsa under controlled illumination. Biol. Bull. mar. biol. Lab., Woods Hole 82: 112-126

Shallek, W. (1943). The reaction of certain Crustacea to direct and diffuse light. Biol. Bull. mar. biol. Lab., Woods Hole 84: 98-105

Smith, R. C., Baker, K. S. (1981). Optical properties of the clearest natural waters $(200-800 \mathrm{~nm})$. Appl. Optics 20 $177-184$

Smith, R. C., Booth, C. R., Star, J. L. (1984). Oceanographic bio-optical profiling system. Appl. Optics 23: 2791-2797

Sokal, R. R., Rohlf, F. J. (1981). Biometry, 2nd edn. W. H. Freeman, San Francisco 
Stearns, D. E., Forward, R. B., Jr (1984a). Photosensitivity of the calanoid copepod Acartia tonsa. Mar. Biol. 82: 85-89

Stearns, D. E., Forward, R. B., Jr. (1984b). Copepod photobehavior in a simulated natural light environment and its relation to nocturnal vertical migration. Mar. Biol. 82: 91-100

Strickler, J. R. (1973). Experimental-ecological investigations into the vertical migration of planktonic crustaceae. Ph. D. dissertation translated from German. Translation Bureau (PFB), Foreign Languages Division, Department of the Environment, Fisheries Research Board of Canada, Biological Station, St. John's Nfld., Canada

Sulkin, S. D. (1984). Behavioral basis of depth regulation in the larvae of brachyran crabs. Mar. Ecol, Prog. Ser 15: $181-205$

Swift, M. C., Forward, R. B., Jr. (1983). Photoresponses of the copepod Mesocyclops edax. J. Plankton Res. 5: 407-415

Verheijen, F. J. (1958). The mechanisms of the trapping effect of artificial light sources upon animals. Archs. néerl. Zool. 13: $1-107$

This article was presented by Dr R. B. Forward, Beaufort, N. Carolina, USA
Widder, E. A., Latz, M. I., Case, J. F. (1983). Marine bioluminescence spectra measured with an optical multichannel detection system. Biol. Bull. mar. biol. Lab., Woods Hole 165: 791-810

Wiebe, P. H., Burt, K. H., Boyd, S. H., Morton, A. W (1976). A multiple opening/closing net and environmental sensing system for sampling zooplankton. J. mar. Res. 34: 313-326

Wiebe, P. H., Morton, A. W., Bradley, A. M., Backus, R. H., Craddock, J. E., Barber, V., Cowles, T J., Flierl, G. R. (1985). New developments in the MOCNESS, and apparatus for sampling zooplankton and micronekton. Mar. Biol. 87: 313-323

Wishner, K. F., Allison, S. K. (1986). The distribution and abundance of copepods in relation to the physical structure of the Gulf Stream. Deep Sea Res. 33: 750-731

Worthington, E. B. (1931). Vertical movements of fresh-water macroplankton. Int. Rev. ges. Hydrobiol. Hydrogr. 25: $394-436$

Manuscript first received: August 29, 1988

Revised version accepted: April 25, 1989 